\title{
Do commodity prices incentivize exploration permit application? An explorative study of an anecdotal relation
}

\author{
Tobias Olofsson ${ }^{1}$
}

Received: 13 July 2020 / Accepted: 8 June 2021 / Published online: 21 June 2021

(C) The Author(s) 2021

\begin{abstract}
Do commodity prices drive exploration permit applications? In a recent qualitative study on mineral exploration and risk management in Sweden, a number of respondents representing mineral exploration organizations and governmental agencies expressed how mineral exploration permit applications increase with rising commodity prices. This paper seeks to investigate this alleged correlation quantitatively. In doing so, the study uses time series analysis and ARIMA models to analyze the covariation of applications for exploration permits filed with the Mining Inspectorate of Sweden and annual average copper, lead, zinc, silver, and gold prices in the period 2000 to 2018. Contrary to the anecdotal evidence given by actors in the exploration and mining industry, the paper cannot show any significant covariation between the majority of mineral prices and applications filed. Contrary to expectations, there appear therefore not to be any correlation between copper, lead, silver, and gold prices and the volume of permit applications filed annually. Moreover, the study also shows that the correlation between annual average zinc prices and permit applications appears to be the reverse of what was first believed as the annual change in application volume occurs before the rise or fall in zinc prices.
\end{abstract}

Keywords Exploration permit applications · Commodity prices · ARIMA $\cdot$ Time series analysis $\cdot$ Mineral exploration

JEL classification $\mathrm{A} 10 \cdot \mathrm{C} 00$

\section{Introduction}

This paper sets out to explore a seemingly simple proposition: that rising commodity prices incentivize explorationists to apply for exploration permits. This link between prices and the volume of exploration permit applications filed in a year was proposed by several informants interviewed for a recent qualitative research project on mineral exploration, forecasting, and uncertainty in Sweden (Olofsson 2020a, 2020b). One example of this claim was provided by a senior officer with the Mining Inspectorate of Sweden (MIS) - the agency which reviews applications for exploration permits. In the interview, the officer said that the inspectorate tends to see a significant increase in the number of permit applications filed with them at times of increasing commodity prices. Another

Tobias Olofsson

tobias.olofson@soc.lu.se

1 Department of Sociology, Lund University, Box 114, 221 00, Lund, Sweden example of this proposition was provided by a mining engineer who explained that exploration companies find it easier to invest in exploration efforts following a rise in commodity prices as climbing prices often mean that there is greater interest from investors, which in turn means that there are usually greater volumes of equity available to explorationists when commodity prices go up. According to the mining engineer, such ebbs and flows in the accessibility of equity are more or less the nature of the game and while, he continued, it would often be preferable to invest counter-cyclically and build a pipeline of projects during bear markets, which could then be moved into production when prices eventually begin to climb again, most exploration and mining companies lack the resources to do so. Therefore, most companies, according to this informant's experience, will usually have to wait for prices to attract investment capital to projects before they can begin spending money on exploration.

On the surface, these claims make sense. Mineral exploration is both time-consuming and heavy on financial resources. Companies that have a number of projects in the desktop or archival stage, it could be suggested, may look at rising 
Graph 1 Annual applications for exploration permits and annual average commodity prices
600
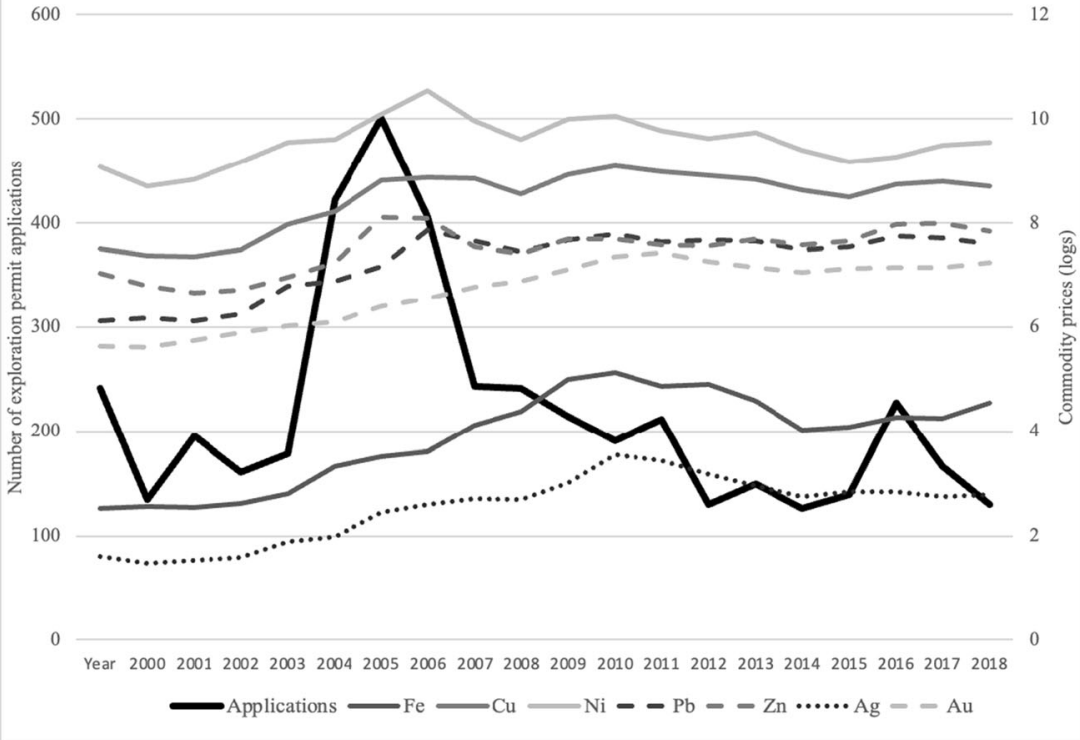

commodity prices and a resulting increase in interest from investors as a window to move into boots-on-the-groundtype work; and to be allowed to put boots on the ground, firms will first need to acquire an exploration permit. Then again, mineral exploration is a high-risk endeavor embedded in a complex institutional framework, there may be many different competing and even counteracting factors involved in the decision-making process behind the choice to file or not to file for an exploration permit. Nevertheless, an initial plot of the number of exploration permits filed with the MIS annually between 2000 and 2019 and the annual average commodity prices for some of the metals and minerals mined in Sweden is inconclusive. Graph 1 shows this plot with the number of applications plotted against the primary y-axis on the lefthand side and commodity prices (in natural logarithms of observed prices) plotted against the secondary y-axis on the right-hand side.

As the plot shows, there appears to be some covariation between the two. The dramatic climb in application filings between 2003 and 2005, for example, coincided with an increase in commodity prices. Then again, the almost equally dramatic fall in exploration permit filing after 2005 appears only to coincide with a fall or plateau in base metal prices while ferrous and precious metals continued to go up in the period. ${ }^{1}$

While the evidence on the surface therefore appears to be inconclusive, there are reasons to expect that prices could drive exploration activities. First, such a relation between commodity prices and exploration levels has been observed elsewhere, i.e., in Canada, where it was found that an increase

\footnotetext{
${ }^{1}$ Note that the combination of natural logs for commodity prices and raw numbers for applications may make the changes in prices appear less dramatic when compared to changes in the number of applications filed each year.
}

in the price of a basket of minerals in the previous year could be linked to an increase in the level of exploration in the next year (Canadian Intergovernmental Working Group on the Mineral Industry 2005). Secondly, the anecdotal evidence for a relation between prices and exploration levels was corroborated by several informants independently of each other. Nevertheless, as the evidence for a link between prices and exploration levels appears to be compelling but inconclusive, it was decided that it would be interesting to explore this anecdotally given connection, and to see whether it could be reproduced quantitatively. The explorative analysis employed an autoregressive integrated moving averages (ARIMA) model to analyze the relation between the number of exploration permits filled with the MIS each year in the period 2000-2019 and the annual average prices for seven non-fuel metal commodities explored for and mined in Sweden. ${ }^{2}$ The model tested the following hypothesis:

H1: The annual number of new applications for exploration permits filed with the Mining Inspectorate of Sweden is positively correlated with movements in mineral commodity prices.

The continuation of this paper explores the hypothesis through the four following sections. The "Background" section places the present explorative study in a broader universe of existing literature on the role of exogenous factors in exploration and mining companies' decision-making. The "Data and model" section outlines the case, describes the dataset used in this analysis and specifies how the ARIMA model was constructed. The "Results" section accounts for the empirical results from the analysis. Above all, the "Discussion"

\footnotetext{
$\overline{2}$ The commodities included were copper, gold, iron ore, lead, nickel, silver, and zinc.
} 
section reports the results for each of the seven bivariate models analyzed and follows up on the results. These results indicated no significant connection between the commodity prices and exploration permit applications except for zinc. The paper concludes with a discussion on the estimated model, the results, and their implications. The discussion ends with a reflection stating that the failure to conclusively confirm or disprove the anecdotal connection between prices and application filings above all opens up for future studies of the relation between exploration and mining company decisionmaking and the exogenous factors influencing these processes.

\section{Background}

Besides the Canadian report mentioned above, the existing literature gives mixed support for a correlation between exploration levels and commodity prices. First, there are evidence that exogenous factors such as price movements may influence the behavior of mineral exploration and mining companies. The structure of the minerals sector and the standardized nature of metal and mineral commodities means that mining firms act as price-takers (Cairns and Lasserre 1986), wherefore prices generally are exogenous to the individual company ${ }^{3}$ and mining firms lack access to market strategies such as branding and labeling available to producers on less standardized "status" markets (Aspers 2005, 2011). Moreover, gold miners have been shown to grow "fatter" during times of increasing commodity prices (Borenstein and Farrell 2007). During booms, gold miners thereby see their value grow concavely with increasing gold prices, indicating a tendency for them to not be able to minimize costs and maximize gains during times of rising gold prices. Following this, it is possible to imagine a situation where mineral explorationists and mining companies cease upon the capital influx that comes with rising commodity prices and use the new capital to finance mineral exploration. Additionally, Mason (1986) makes a strong argument for the importance of external factors such as commodity prices but also exploration information availability. According to Mason, firms have a tendency to over-explore in situations when they expect future commodity prices to be high, and to underexplore when future prices are expected to be low. Nevertheless, while these sources support the idea that commodity price fluctuations influence exploration companies' decision-making - incentivizing or deterring them from investing in exploration depending on the direction that the

\footnotetext{
${ }^{3}$ While prices are usually exogenous to the individual company, there are of course certain things mining companies can do to influence the price they receive, e.g., reduce the amount of impurities or raise the grade in their product.
}

market is moving in, other evidence appear to question such correlations.

Surveys of mining and exploration companies, for example, have not identified commodity prices as important factors when firms make decisions about when and where to carry out mineral exploration (Johnson 1990; Otto et al. 2006). Following from this background, the existing evidence for a correlation between the volume of exploration permits filed and commodity prices is inconclusive. Structural factors appear to open up for such a correlation as price-taking, and the changes in available financial resources in gluts and booms together with the evidence for exogenous factors influencing companies' decision-making speak in favor of such a link. However, the survey's finding that mining companies do not rank commodity prices among the most important factors in investment decision-making speaks against the hypothesis.

\section{Data and model}

As the existing evidence for a connection between exploration activities and commodity prices specifically mention exploration levels, often in terms of the number of exploration permits filed, as being indicative of this relation, this study uses data on applications filed with the MIS as the dependent variable. An additional reason for why increased filings for exploration permits may be indicative of a greater increase in exploration activities can be found in the role exploration permits play in Sweden. An exploration permit offers its holder the exclusive right to undertake exploration in a designated area, and it is the first permit ${ }^{4}$ explorationists need to apply for in order to conduct fieldwork. Permits are awarded based on an assessment by the MIS of the possibility for discovery in the area in question and of the applicant's ability to carry out exploration within this area, that is, if the applicant is believed to have access to sufficient resources for the job. ${ }^{5}$ Because its position in the institutional framework surrounding exploration work in Sweden, exploration permits may therefore be a good indicator of exploration activities as they form an institutional threshold between early stage desktop and archival exploration and intermediate stage boots-on-the-ground exploration. ${ }^{6}$ Then again, the strength of exploration permits as an indicator

\footnotetext{
${ }^{4}$ After obtaining an exploration permit, explorationists will need to draft a workplan and get it approved by stakeholders and the MIS before they can bring vehicles onto the site to carry out geophysical survey work or drilling. However, non-invasive work on foot or skis is allowed prior to the approval of a workplan.

${ }^{5}$ These prerequisites to obtaining exploration permits mean that permits are not awarded for exploration within previously explored areas (unless the applicant can provide good reason for why the area should be re-worked) and that applications for larger areas than the MIS deem workable in a 3year period, given the resources available to the applicant, will not be granted. ${ }^{6}$ For a more detailed outline of the institutions that regulate exploration in Sweden and of the regulatory process, see Olofsson (2020b).
} 
of overall trends in the exploration and mining industry is of secondary nature here, as the primary focus is to explore the direct relation between permit applications and commodity prices.

The dataset was assembled by pooling data from the MIS and the International Monetary Fund (IMF). Data on the number of exploration permit applications filed with the agency is made available by the MIS though their webpages. ${ }^{7}$ The information provided by the MIS includes the total number of applications filed, the number of extensions of permits applied for, the number of permits awarded, and the number of denied applications per year. Unfortunately, only the annual data is available through the MIS webpages and as data is only available from 2000 and onwards. Due to this limitation, the time series generated from these data is unusually short. Short time series are potentially problematic as they may be unable to produce relevant results. However, as this paper only concerns an initial exploration of a relation between permit application filing and commodity prices in Sweden, it was decided to go ahead nevertheless as this was the data available at the time of this investigation. Nevertheless, with these data limitations in mind, follow-up studies are encouraged pending future improvements in data availability.

As the aim was to explore the relation between overall permit application activity and commodity prices, both new permit applications and applications for extensions were initially included in the dependent variable. However, when the resulting index was evaluated, it was noticed that the inclusion of applications for extensions caused severe autocorrelation in the variable. The source of this error was determined to be how exploration permits in Sweden are only valid for 3 years before they need to be extended. Because of this legal artifact, observations (i.e., applications) may re-enter the dataset at regular intervals. The final index was therefore specified to include only applications for new permits. This resulted in a dependent variable for which observations range between a low of 126 and a maximum of 500. The calculated mean of the number of new exploration permit applications filed yearly was approximately 220 between 2000 and 2019 . The year that saw the lowest number of filings was 2015, and the year that saw the highest number of permits applied for was 2006 .

Information on commodity prices for the same period was gathered from the IMF's Primary Commodity Price System (International Monetary Fund 2021). The data consisted of annual average commodity prices as per the largest import market for each given commodity. An overview of the annual commodity prices is provided in Table 1 below. Note that the prices for copper, lead, and zinc are given in USD/metric ton

\footnotetext{
${ }^{7}$ Statistics for the annual number of exploration permits filed with the MIS is available through the agency's website: www.sgu.se/bergsstaten/statistik/ undersokningstillstand.
}

Table 1 Descriptive statistics - commodity prices

\begin{tabular}{llllll}
\hline & Obs. & Mean & Std. Dev. & Min & Max \\
\hline $\mathrm{Fe}$ & 20 & 66.6735 & 48.56381 & 12.45 & 167.79 \\
$\mathrm{Cu}$ & 20 & 5343.439 & 2330.129 & 1560.29 & 8823.45 \\
$\mathrm{Ni}$ & 20 & $15,488.09$ & 7291.241 & 5969.63 & 37.135 .84 \\
$\mathrm{~Pb}$ & 20 & 1624.346 & 731.1884 & 452.25 & 2579.12 \\
$\mathrm{Zn}$ & 20 & 1943.57 & 776.1839 & 778.9 & 3266.18 \\
$\mathrm{Ag}$ & 20 & 14.924 & 8.476962 & 4.37 & 35.11 \\
$\mathrm{Au}$ & 20 & 934.486 & 470.7085 & 271.05 & 1668.82 \\
\hline
\end{tabular}

while the prices for gold and silver are denoted in USD/tr. oz. Moreover, while the descriptive statistics provided here describe prices as given in the IMF data, all analyses presented in this paper used logarithms of prices.

Augmented Dickey-Fuller tests were carried out to investigate the presence of unit roots in all variables. The results of these analyses indicated that both the dependent and the independent variables to have unit roots and thereby to be nonstationary. Because of this, additional Dickey-Fuller tests were carried out on differentiated variables. These tests showed all difference variables to be stationary at first difference except the annual average gold prices, which where instead showed to be stationary first at the second difference level. In addition to this, diagnostics for autocorrelation (AC) as well as for partial autocorrelation (PAC) where carried out on the dependent variable. The outcome showed that the number of exploration permit applications was subject to $\mathrm{AC}$ and $\mathrm{PAC}$ at lag 1, i.e., the number of permits filed in year 1 correlated with the number of permits filed in year 0 . A second round of model diagnostics confirmed the decision to use the differentiated variable as these were found to be stationary and $\mathrm{AC}$ and PAC tests for the differentiated dependent variable did not show significant autocorrelation. The results of the AC and PAC analyses for the dependent variable are shown in Graphs 2, 3, 4, and 5 below.

\section{Model}

The ARIMA model was specified with one bivariate model created for each commodity. Separate models were thereby specified for the seven major industrial and precious metals. The selection of independent variables was made in relation to a review of the most common metals and minerals mined for in Sweden (Geological Survey of Sweden 2020). As a result of this, separate models were created for iron ore $(\mathrm{Fe})$ copper $(\mathrm{Cu})$, nickel $(\mathrm{Ni})$, lead $(\mathrm{Pb})$, zinc $(\mathrm{Zn})$, silver $(\mathrm{Ag})$, and gold $(\mathrm{Au})$. As ARIMA models require stationary data, the model was specified using differentiated dependent and independent variables to manage the presence of unit roots (nonstationarity) as well as the autocorrelation in the dependent 
Graph 2 Autocorrelations number of applications filed annually

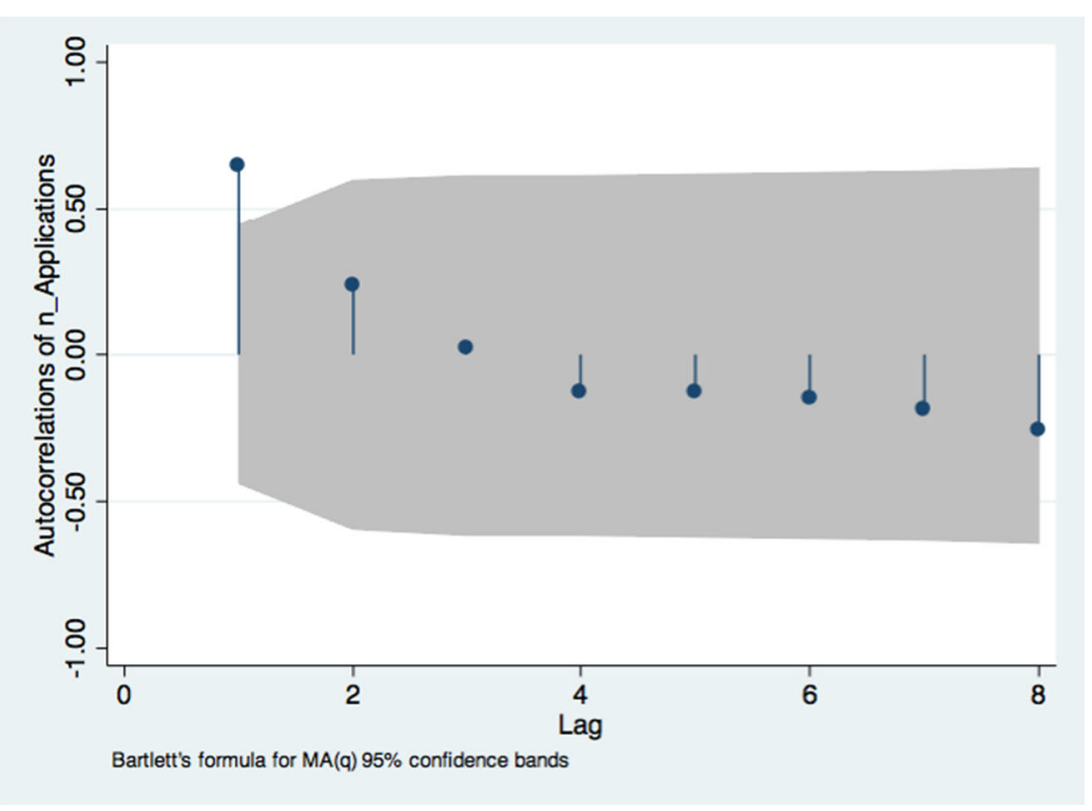

variable. The final model was therefore specified as a differentiated time series according to as follows: ${ }^{8}$

$$
\Delta \mathrm{Y}_{\mathrm{t}}=\Delta \mathrm{bX}_{\mathrm{t}}+\Delta \mathrm{N}_{\mathrm{t}}
$$

Except for the gold model, which because of gold prices only being stationary at the second difference, it was specified with the second-order difference.

Models producing significant results were then tested for correlations in the residuals by controlling for autocorrelation and moving averages.

\section{Results}

Contrary to the anecdotal evidence for a positive correlation between commodity prices and exploration permit application filings, the majority of the models did not indicate a significant correlation between commodity prices and changes in in the number of permit applications filed. Table 2 shows the resulting coefficients and standard errors for each of the seven bivariate models. As is shown in the table, the results for iron ore, copper, nickel, lead, silver, and gold all returned nonsignificant results, and t-test values returned were well below the 95\% confidence threshold. However, the model for zinc shows a positive correlation between differences in commodity prices and differences in the number of permit applications filed with the MIS. Based on the resulting coefficient, a change of approximately $1 \%$ in annual average zinc prices (all else equal) is estimated to correlate with a change of \pm 1.896 applications in the MIS's inbox the same year. While the effect of price movements on application frequencies is

\footnotetext{
${ }^{8}$ For a detailed account of autoregression and the specification of differentiated models, see Skog (1988).
}

relatively small, this result is more or less in line with the connection between prices and applications that informants in the aforementioned qualitative study described. Nevertheless, while zinc is an important metal in the Swedish mining sector ${ }^{9}$ and is produced at the majority of the non-ferrous mines in the country, the results only partially support the story that commodity prices in general drive the number of exploration permits filed for annually. Remember, according to the anecdote, commodity prices not the price of one commodity are supposed to be related to the number of exploration permit applications.

Because of this discrepancy between the qualitative evidence and the outcome of the analysis presented here, further analyses were undertaken. First, the model was respecified with the lagged independent variables to explore whether the relationship between permit application filings and commodity prices consists of a delayed response, that is, that it is the previous year's prices that incentivize explorationists to apply for exploration permits or that budget constraints limit explorationists' ability to immediately react to movements in commodity prices and that decisions to file for exploration permit applications therefore get delayed by up to 1 year (see Eggert and Roderick 1987). The lagged commodity price variables were treated in the same way the non-lagged variables had been in the previously described model. The results of these analyses are presented in Table 3 and did not contain significant results.

Failing to produce significant results, the lagged dependent variable model cast additional doubt on the proposed relation between commodity prices and the number of exploration

\footnotetext{
${ }^{0}$ In 2019, zinc made up approximately $47 \%$ of the non-ferrous mineral mined in Sweden (Geological Survey of Sweden 2020).
} 
Graph 3 Partial autocorrelations — number of applications filed annually

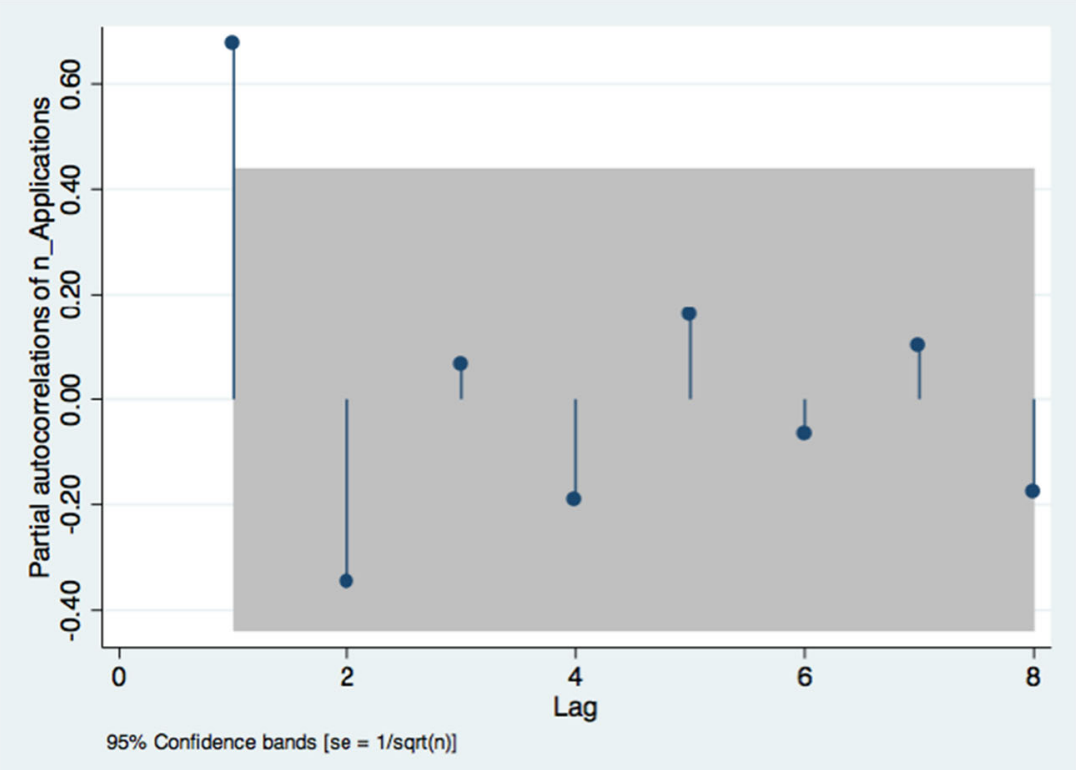

permit applications filed with the MIS. Moreover, the lack of an identifiable significant correlation between the lagged application variable and zinc prices needs additional consideration. Given the nonsignificant results of the lagged dependent variable model, it appears unlikely that explorationists are incentivized by or act on last year's zinc prices. Instead, the reaction appears to be more immediate, occurring in the same year. Nevertheless, while such an explanation is plausible given the results of the analysis presented here, it is believed that there may be more plausible explanations that lie beyond the scope of this analysis. One such explanation is the possibility that the correlation identified in the original model (but lacking in the lagged model) could be the result of some confounding factor. As surveys of decision-making processes in mineral exploration show (Johnson 1990; Otto et al. 2006; see background section above), many different factors are involved in the decision to invest in and move forward with an exploration project (see also Olofsson 2022b). Perhaps some of these factors depend on some trend or input that covaries with zinc prices?

In order to explore for a confounding factor, additional investigations were carried out by analyzing for potential
Graph 4 Autocorrelations difference of number of applications filed annually

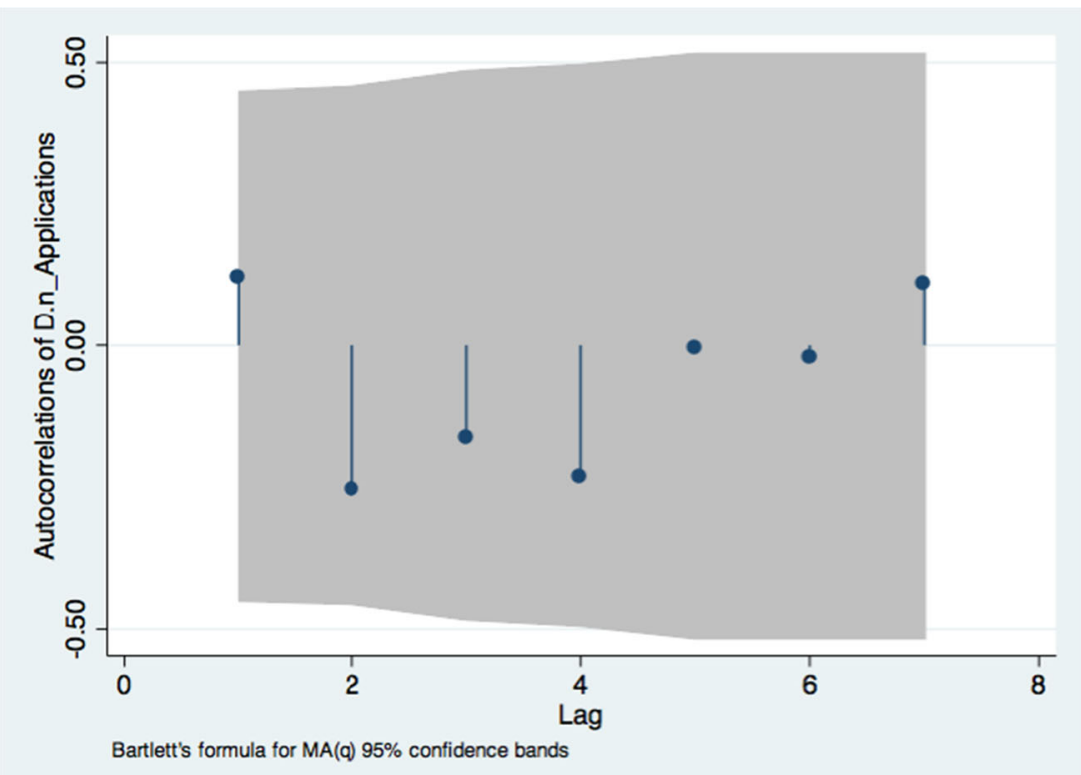


Graph 5 Partial autocorrelations — difference of number of applications filed annually

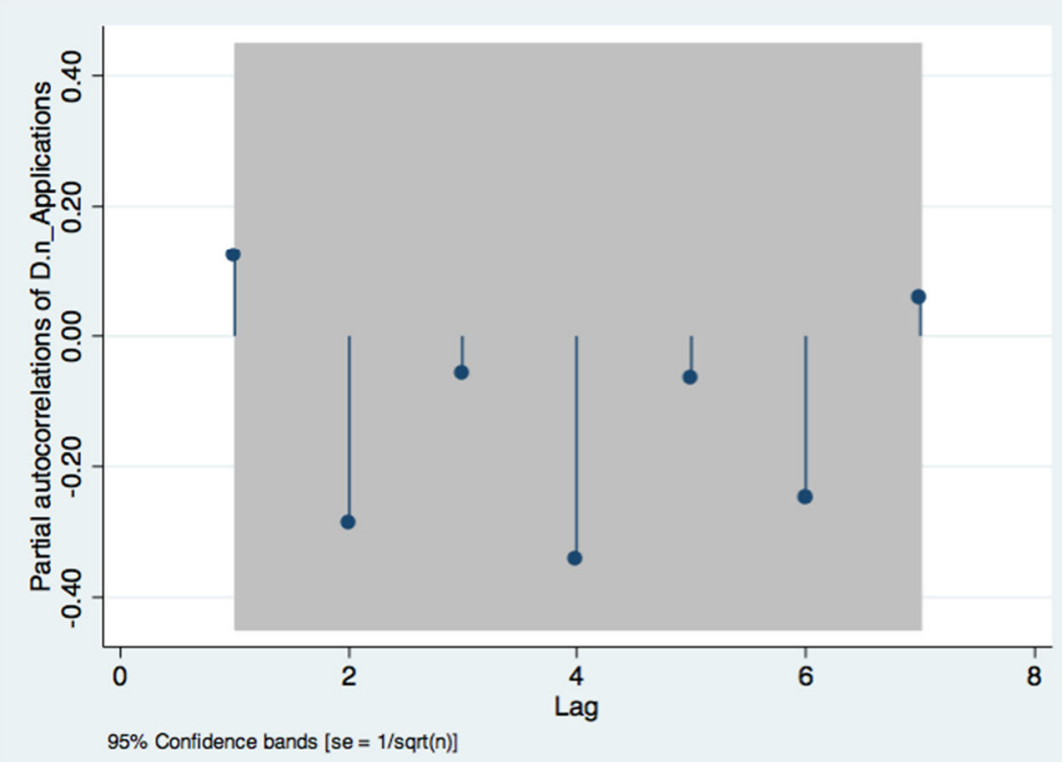

cointegration between commodity prices and applications filed annually in Sweden, that is, that prices and permit applications, while not correlated in the short-term, may be correlated in the long term - i.e., through a confounding factor. Moreover, if the variables could be shown to be cointegrated, the ambition was to then estimate an error correction model to better describe the relation between prices and permit applications in the dataset. However, Engle-Granger testing for cointegration did not indicate significant covariation as the test statistic for a linear combination did not exceed the critical value defined by MacKinnon (2010). As a result of this, attempts to estimate an error correction model were abandoned.

\section{Discussion}

Based on the results of this explorative analysis, there appears to be some evidence for a correlation between changes in annual average zinc prices and the number of exploration permit applications filed with the MIS. In this case, differences in the number of applications filed per year have been shown to positively correlate with the difference in average zinc prices. However, while these results to some extent confirm the experiences of the informants interviewed for the qualitative study discussed above, the evidence do not appear to support a correlation of the extent proposed by the

Table 2 ARIMA time series with differentiated variables

\begin{tabular}{|c|c|c|c|c|c|c|c|}
\hline & $\begin{array}{l}1 \\
\mathrm{Fe}\end{array}$ & $\begin{array}{l}2 \\
\mathrm{Cu}\end{array}$ & $\begin{array}{l}3 \\
\mathrm{Ni}\end{array}$ & $\begin{array}{l}4 \\
\mathrm{~Pb}\end{array}$ & $\begin{array}{l}5 \\
\mathrm{Zn}\end{array}$ & $\begin{array}{l}6 \\
\mathrm{Ag}\end{array}$ & $\begin{array}{l}7 \\
\mathrm{Au} \dagger\end{array}$ \\
\hline $\mathrm{b}$ & 28.70 & 141.4 & 81.56 & 34.68 & $189.6^{* *}$ & 62.72 & 91.31 \\
\hline SE & $(90.25)$ & (159.6) & (69.08) & (86.84) & $(59.87)$ & (150.3) & $(250.0)$ \\
\hline Constant & $\begin{array}{l}-8.890 \\
(36.00)\end{array}$ & $\begin{array}{l}-14.76 \\
(21.89)\end{array}$ & $\begin{array}{l}-7.892 \\
(22.85)\end{array}$ & $\begin{array}{l}-8.545 \\
(23.52)\end{array}$ & $\begin{array}{l}-13.98 \\
(22.19)\end{array}$ & $\begin{array}{l}-9.753 \\
(24.94)\end{array}$ & $\begin{array}{l}-0.897 \\
(22.52)\end{array}$ \\
\hline \multicolumn{8}{|l|}{ sigma } \\
\hline Constant & $\begin{array}{l}84.95^{\text {*** }} \\
(12.53)\end{array}$ & $\begin{array}{l}78.73^{* * * *} \\
(16.58)\end{array}$ & $\begin{array}{l}81.60^{\text {**** }} \\
(11.56)\end{array}$ & $\begin{array}{l}84.95^{* * *} \\
(11.58)\end{array}$ & $\begin{array}{l}67.06^{* * *} \\
(10.92)\end{array}$ & $\begin{array}{l}84.23^{\text {**** }} \\
(11.14)\end{array}$ & $\begin{array}{l}83.50^{\text {**** }} \\
(11.82)\end{array}$ \\
\hline $\mathrm{n}$ & 19 & 19 & 19 & 19 & 19 & 19 & 18 \\
\hline
\end{tabular}

Standard errors in parentheses

$Y$ number of exploration permit applications

${ }^{*} \mathrm{p}<0.05$

*** $\mathrm{p}<0.01$

**** $\mathrm{p}<0.001$

All variables are differentiated. $†$ Second-order difference used 
Table 3 ARIMA time series with differentiated variables and lagged commodity prices

\begin{tabular}{|c|c|c|c|c|c|c|c|}
\hline & $\begin{array}{l}1 \\
\text { Fe L1 }\end{array}$ & $\begin{array}{l}2 \\
\mathrm{Cu} \mathrm{L} 1\end{array}$ & $\begin{array}{l}3 \\
\mathrm{Ni} \text { L1 }\end{array}$ & $\begin{array}{l}4 \\
\mathrm{~Pb} \mathrm{~L} 1\end{array}$ & $\begin{array}{l}5 \\
\mathrm{Zn} \mathrm{L1}\end{array}$ & $\begin{array}{l}6 \\
\text { Ag L1 }\end{array}$ & $\begin{array}{l}7 \\
\mathrm{Au} \mathrm{L} 1 \dagger\end{array}$ \\
\hline $\mathrm{b}$ & 37.29 & 44.03 & -34.55 & 13.18 & -13.69 & 33.40 & 61.35 \\
\hline SE & (137.1) & (89.49) & $(82.66)$ & (76.61) & (97.58) & (134.1) & (181.7) \\
\hline Constant & $\begin{array}{l}-3.859 \\
(27.08)\end{array}$ & $\begin{array}{l}-3.410 \\
(29.01)\end{array}$ & $\begin{array}{l}0.525 \\
(29.76)\end{array}$ & $\begin{array}{l}-1.447 \\
(38.82)\end{array}$ & $\begin{array}{l}0.446 \\
(25.92)\end{array}$ & $\begin{array}{l}-2.419 \\
(32.19)\end{array}$ & $\begin{array}{l}-3.964 \\
(25.58)\end{array}$ \\
\hline \multicolumn{8}{|l|}{ sigma } \\
\hline Constant & $\begin{array}{l}83.58^{* * * *} \\
(11.59)\end{array}$ & $\begin{array}{l}83.60^{* * * *} \\
(13.82)\end{array}$ & $\begin{array}{l}83.54^{* * * *} \\
(11.55)\end{array}$ & $\begin{array}{l}84.19^{* * * *} \\
(11.17)\end{array}$ & $\begin{array}{l}84.15^{* * * *} \\
(11.94)\end{array}$ & $\begin{array}{l}83.91^{* * * *} \\
(12.50)\end{array}$ & $\begin{array}{l}85.03^{\text {**** }} \\
(12.10)\end{array}$ \\
\hline $\mathrm{n}$ & 18 & 18 & 18 & 18 & 18 & 18 & 17 \\
\hline
\end{tabular}

Standard errors in parentheses

$Y$ number of exploration permit applications

* $\mathrm{p}<0.05$

*** $\mathrm{p}<0.01$

**** $\mathrm{p}<0.001$

All variables are differentiated. $†$ Second-order difference used

informants. The evidence for such a relation between exploration applications and commodity prices therefore remains vague. This should be read in relation to the existing literature on the influence of exogenous factors' importance in exploration decisions. That exogenous factors do play a role has been suggested (Mason 1986) and surveyed (Johnson 1990; Otto et al. 2006). Nevertheless, the literature on exogenous factors' role in explorationists' decision-making has shown that many different factors play a role in mining companies' decisions and that while commodity prices are one such factor, other factors tend to weigh heavier in explorationists' decisionmaking than do commodity prices and than do many other factors.

It should be noted that this study has only provided a brief exploration of the possible relation between commodity prices and exploration permit applications. The results presented here tie into a larger conversation about the role of exogenous factors in exploration and mining companies' decision-making and because the model has apparent limitations, this paper can only point toward relevant objections in terms of uncertainties and ambiguities regarding whether commodity prices causally drive changes in exploration application filing, and if so, exactly what role commodity prices play in the decisionmaking processes that leads explorationists to file applications. Further work is therefore required if this question is to be resolved. One first step that ought to be taken is to perform the analysis with longer time series. The time series employed here are very short and therefore prone to type 1 errors (Skog 1988), and future research may consider either using data covering a longer period of time or investigating opportunities to use quarterly rather than annual data. ${ }^{10}$ Future research may also look to other types of outcomes related to exploration permit applications and overall exploration activity. One such outcome could be changes in exploration expenditures or changes in the size of areas applied for in permit applications. Both these dimensions may better describe changes in exploration decisions in relation to market movements. Falling prices may incentivize explorationists to home in their exploration efforts on smaller areas in order to conserve financial and organizational resources, that is, to continue exploration but with smaller exploration crews. Likewise, rising prices may usher in more optimistic spending and cause exploration budgets to swell. Still, many factors play a role in explorationists' decisionmaking and while annual changes in commodity prices may influence the expectations held by explorationists and thereby shift their decisions toward the more optimistic or pessimistic, prices are only one among many exogenous and endogenous factors. Nevertheless, while these are important questions to investigate in future research, this paper has first and foremost sought to ground anecdotal evidence provided by informants through quantitative analysis, and the result of this effort is a small confirmation of a positive relation between (some) commodity prices and the number of applications filed with the MIS but also a reminder that the question is far more nuanced and too complex to be answered in a small explorative study.

\footnotetext{
10 This possibility was investigated already in relation to this paper, but since no quarterly exploration application data was readily available from the MIS, it was decided that this venue of research best be left for future investigations as time limitations did not allow for such a database to be constructed from scratch (e.g., by going through MIS archives and catalogizing applications by quarter).
} 
Acknowledgements The author wishes to thank the anonymous reviewers for their helpful suggestions and Jonas Bååth and Ilkka Henrik Mäkinen who commented on early versions of this paper.

Code availability Not applicable

Funding Open access funding provided by Lund University. The project was funded through a faculty-financed $\mathrm{PhD}$ candidacy with the Faculty of Social Science at Uppsala University.

Data availability Only publicly available data from sgu.se, sgu.se/ bergsstaten, and the International Monetary Fund (imf.com) have been used for this study.

\section{Declarations}

Conflict of interest The author declares no competing interests.

Open Access This article is licensed under a Creative Commons Attribution 4.0 International License, which permits use, sharing, adaptation, distribution and reproduction in any medium or format, as long as you give appropriate credit to the original author(s) and the source, provide a link to the Creative Commons licence, and indicate if changes were made. The images or other third party material in this article are included in the article's Creative Commons licence, unless indicated otherwise in a credit line to the material. If material is not included in the article's Creative Commons licence and your intended use is not permitted by statutory regulation or exceeds the permitted use, you will need to obtain permission directly from the copyright holder. To view a copy of this licence, visit http://creativecommons.org/licenses/by/4.0/.

\section{References}

Aspers P (2005) Status markets and standard markets in the global garment industry. Max Planck Institute for the Study of Societies, Cologne, Germany
Aspers P (2011) Markets. Polity Press, Cambridge, UK

Borenstein S, Farrell J (2007) Do investors forecast fat firms? Evidence from the gold-mining industry. RAND J Econ 38(3):626-647

Cairns RD, Lasserre P (1986) Sectoral supply of minerals of varying quality. Scand J Econ 88(4):605-626

Canadian Intergovernmental Working Group on the Mineral Industry (2005) Overview of trends in Canadian mineral exploration. Minister of Public Works and Government Services Canada, Ottawa, Ont

Eggert, Roderick G (1987) Metallic mineral exploration: an economic analysis. Resources for the Future, Washington, D.C

Geological Survey of Sweden (2020) Bergverksstatistik 2000-2019. SGU, Uppsala, Sweden

International Monetary Fund (2021) "Primary commodity price system." Retrieved March 30, 2021 (https://data.imf.org/?sk=0f82aa45-48a74431-8873-b46d3a6d507a\&hide_uv=1\&sId=1547558078595)

Johnson CJ (1990) Ranking countries for minerals exploration. Nat Res Forum 14(3):178-186

MacKinnon JG (2010) Critical values for cointegration tests. In: Working Paper 1227. Queen's University, Economics Department

Mason CF (1986) Exploration, information, and regulation in an exhaustible mineral industry. J Environ Econ Manag 13:153-166

Olofsson T (2020a) Imagined futures in mineral exploration. J Cult Econ 12(3):265-277

Olofsson T (2020b) Mining futures: predictions and uncertainty in Swedish mineral exploration. PhD Dissertation. Uppsala University, Uppsala, Sweden

Otto J, Andrews C, Cawood F, Doggett M, Guj P, Stermole F, Stermole J, Tilton J (eds) (2006) Mining royalties: a global study of their impact on investors, government, and civil society. World Bank, Washington, DC

Papp JF, Bray EL, Edelstein DL, Fenton MD, Guberman DE, Hedrick JB, Jorgenson JD, Kuck PH, Shedd KB, Tolcin AC (2008) Factors that influence the price of $\mathrm{Al}, \mathrm{Cd}, \mathrm{Co}, \mathrm{Cu}, \mathrm{Fe}, \mathrm{Ni}, \mathrm{Pb}$, rare earth elements, and Zn. US Geological Survey Open-File Report 1356

Skog O-J (1988) Testing casual hypotheses about correlated trends: pitfalls and remedies. Contemporary Drug Problems 15:565-606

Publisher's note Springer Nature remains neutral with regard to jurisdictional claims in published maps and institutional affiliations. 